\title{
Pengembangan Multimedia Interaktif Berbasis PBL Pada Materi Gerak Parabola Untuk Meningkatkan Hasil Belajar Peserta Didik
}

\author{
${ }^{1}$ Abdul Halim Rohman, ${ }^{2}$ Kosim, ${ }^{3}$ I Wayan Gunada, ${ }^{4}$ Hikmawati \\ ${ }^{1,2,3}$ Prodi Pendidikan Fisika, FKIP, Universitas Mataram, Jln. Majapahit No. 62, Gomong, \\ Kecamatan Selaparang, Kota Mataram, Nusa Tenggara Barat, 83115 \\ Email Korespondensi: Rohman0498@gmail.com
}

\begin{tabular}{|c|c|}
\hline Arti & bstract \\
\hline $\begin{array}{l}\text { Article History } \\
\text { Received: 09 Nov } 2021 \\
\text { Revised: } 22 \text { Dec } 2021 \\
\text { Published: } 30 \text { Dec } 2021\end{array}$ & \multirow[b]{2}{*}{$\begin{array}{l}\text { The process of learning physics at various levels of education is still faced with } \\
\text { several difficulties, especially the use of interactive multimedia which is still } \\
\text { lacking so that educators are required to innovate to develop interactive } \\
\text { multimedia to increase interest in learning and student learning outcomes. This } \\
\text { research is a development research that aims to produce interactive } \\
\text { multimedia based on problem based learning that is valid, effective, and } \\
\text { practical to improve student learning outcomes on parabolic motion material. } \\
\text { The research development model used in this study is a } 4 D \text { (four D) model } \\
\text { consisting of define, design, develop and disseminate. The instruments in this } \\
\text { development research consist of interactive multimedia, syllabus, lesson plans, } \\
\text { LKPD, test instruments. The data collection techniques used in this study were } \\
\text { expert validation, limited trials and student responses. The results showed that } \\
\text { interactive multimedia had an average score of } 3.12 \text { with a very good category, } \\
\text { the syllabus had a score of } 78.08 \% \text { with a very valid category, lesson plans had } \\
\text { a score of } 73.66 \% \text { with a fairly valid category, LKPD had a score of } 75.50 \% \\
\text { with a very valid category and the test instrument has a score of } 77.60 \% \text { with a } \\
\text { very valid category. Interactive multimedia based on problem based learning is } \\
\text { effectively used with an average score of } 3.04 \text { with a very good category and is } \\
\text { effectively used because there is an increase in learning outcomes with an } N \text { - } \\
\text { gain value of } 0.49 \text { having a medium category. Interactive multimedia based on } \\
\text { problem based learning on parabolic motion material is valid, practical, and } \\
\text { effectively used in learning so that it is suitable for use in the learning process } \\
\text { and proven to improve students' cognitive learning outcomes }\end{array}$} \\
\hline $\begin{array}{l}\text { Keywords } \\
\text { writing instructi } \\
\text { prism journal; } \\
\text { article template }\end{array}$ & \\
\hline S1 Artikel & Abstrak \\
\hline $\begin{array}{l}\text { Sejarah Artikel } \\
\text { Diterima: 09 Nov } 2021 \\
\text { Direvisi: 22 Des } 2021 \\
\text { Dipublikasi: } 30 \text { Des } 2021\end{array}$ & \multirow{2}{*}{$\begin{array}{l}\text { Proses pembelajaran fisika pada berbagai jenjang pendidikan masih dihadapkan } \\
\text { pada beberapa kesulitan khusunya penggunaan multimedia interaktif yang } \\
\text { masih kurang sehingga tenaga pendidik diharuskan untuk melakukan inovasi } \\
\text { untuk melakukan pengembangan multimedia interaktif untuk meningkatkan } \\
\text { minat belajar dan hasil belajar peserta didik. Penelitian ini merupakan } \\
\text { penelitian pengembangan yang bertujuan untuk menghasilkan multimedia } \\
\text { interaktif berbasis problem based learning yang valid, efektif, dan praktis } \\
\text { untuk meningkatkan hasil belajar peserta didik pada materi gerak parabola. } \\
\text { Model penelitian pengembangan yang digunakan dalam penelitian ini adalah } \\
\text { model 4D (four D) yang terdiri dari define, design, develop dan disseminate. } \\
\text { Instrumen dalam penelitian pengembangan ini terdiri dari multimedia inteaktif, } \\
\text { silabus, RPP, LKPD, instrumen tes. Teknik pengumpulan data yang digunakan } \\
\text { dalam penelitian ini yaitu validasi ahli, uji coba terbatas dan respons peserta } \\
\text { didik. Hasil penelitian menujukan bahwa multimedia interaktif memiliki skor } \\
\text { rata- rata } 3,12 \text { dengan kategori sangat baik, silabus memiliki skor } 78,08 \% \\
\text { dengan kategori sangat valid, RPP memiliki skor } 73,66 \% \text { dengan kategori } \\
\text { cukup valid, LKPD memiliki skor } 75,50 \% \text { dengan kategori sangat valid dan } \\
\text { instrumen tes memiliki skor } 77,60 \% \text { dengan kategori sangat valid. Multimedia } \\
\text { interaktif berbasis problem based learning efektif digunakan dengan skor rata- } \\
\text { rata } 3,04 \text { dengan kategori sanga baik dan efektif digunaan karena terdapat }\end{array}$} \\
\hline $\begin{array}{l}\text { Kata kunci } \\
\text { Petunjuk penulis } \\
\text { Jurnal prisma; } \\
\text { template artikel }\end{array}$ & \\
\hline
\end{tabular}


peningkatan hasil belajar dengan nilai $\mathrm{N}$-gain sebesar 0,49 memiliki kategori sedang. Multimedia interaktif berbasis problem based learning pada materi gerak parabola valid, praktis, dan efektif digunakan dalam pembelajaran sehingga layak digunakan dalam proses pembelajaran dan terbukti meningkatkan hasil belajar kognitif peserta didik

Sitasi: Rohman, A.H., Kosim, K., Gunada, I.W., \& Hikmawati, H. (2021 Pengembangan Multimedia Interaktif Berbasis PBL Pada Materi Gerak Parabola Untuk Meningkatkan Hasil Belajar Peserta Didik, Kappa Journal. 5(2), 231-239

\section{PENDAHULUAN}

Pendidikan memiliki pengaruh penting bagi kemajuan suatu negara untuk menciptakan generasi penerus bangsa yang cerdas, aktif, kreatif dan memiliki moral yang baik. Undang-undang No.20 tahun 2003 tentang sistem pendidikan nasional, menjelaskan bahwa yang dimaksud pendidikan adalah usaha sadar dan terencana untuk mewujudkan susunan belajar dan proses pembelajaran agar peserta didik secara aktif mengembangkan potensi dirinya untuk memiliki kekuatan spiritual keagamaan, pendidikan diri, kepribadian, kecerdasan, akhlak mulia, serta keterampilan yang diperlukan dirinya, masyarakat, bangsa dan negara. Pendidikan bertujuan untuk mengembangkan potensi siswa agar menjadi manusia yang beriman dan bertakwa terhadap Tuhan yang maha esa, berakhlak mulia, sehat, berilmu, dan bertanggung jawab. Untuk mewujudkan tujuan pendidikan, tenaga pendidik dituntut lebih kreatif dalam menciptakan suasana belajar yang menyenangkan guna menarik perhatian dan minat peserta didik dalam proses pembelajaran menggunakan model dan media pembelajaran (Awwaliyah, 2018). Proses pembelajaran fisika pada berbagai jenjang pendidikan masih dihadapkan pada beberapa kesulitan khusunya penggunaan media pembelajaran. Media pembelajaran merupakan alat bantu dalam proses pembelajaran yang harus memiliki sifat menarik, interaktif, kesesuaian dengan materi pembelajaran fisika yang akan diajarkan, mudah digunakan oleh siswa, efektif dan menghemat waktu pembelajaran sehingga menciptakan suasana menyenangkan dalam proses pembelajaran fisika (Rahmawati \& dewi, 2019). Pemanfaatan media pembelajaran yang masih kurang menyebabkan rendahnya motivasi peserta didik untuk belajar karena merasa jenuh dengan media pembelajaran yang sederhana dan kurang variatif yaitu gambar yang tersedia pada buku dan benda konkret yang ada disekitar sekolah. Rendahnya motivasi peserta didik dalam proses pembelajaran berdampak terhadap hasil belajarnya. Masalah berikutnya adalah kesulitan guru dalam menjelaskan konsep-konsep fisika yang abstrak kepada peserta didiknya. Oleh karenanya diperlukan adanya media pembelajaran yang lebih baik (Syahidi et al., 2020) Peserta didik lebih tertarik apabila penggunaan media pembelajaran berupa video, gambar dan animasi selama proses pembelajaran, serta beberapa kali guru juga menggunakan power point dan video sebagai media pembelajaran (Rafmana et al., 2018). Penggunaan media pembelajaran yang tepat akan memaksimalkan perolehan manfaat-manfaat dari penggunaan media di antaranya adalah proses pembelajaran menjadi lebih jelas dan menarik, lebih interaktif, efisiensi dalam waktu dan tenaga serta dapat meningkatkan kualitas hasil belajar peserta didik. Sejalan dengan penelitian Wiyono (2015) mengatakan bahwa pengembangan multimedia interaktif berbasis model problem based learning telah memenuhi kriteria valid, praktis dan memberikan dampak positif terhadap hasil belajar peserta didik. Oleh karena itu, dibutuhkan suatu model dan media pembelajaran yang berkaitan dengan penjelasan konsepkonsep fisika tersebut dan membuat peserta didik lebih aktif. Untuk mengatasi permasalahan yang terjadi pada peserta didik maka peneliti menggunakan model problem based learning dan media pembelajaran yaitu multimedia interaktif untuk meningkatkan hasil belajar peserta didik . 
Multimedia interaktif adalah suatu program pembelajaran yang berisi kombinasi teks, gambar, grafik, suara, video, animasi, simulasi secara terpadu dan sinergis dengan bantuan perangkat komputer atau sejenisnya untuk mencapai tujuan pembelajaran tertentu dimana pengguna dapat secara aktif berinteraksi dengan program komputer (Surjono, 2017). Multimedia interaktif yang dikembangkan untuk peroses pembelajaran dibuat dengan menggunakan aplikasi Adobe Flash Professional CS6 dan akan dikombinasikan dengan model problem based learning yang tujuannya untuk menarik minat dan membuat peserta didik aktif dalam kegiatan belajar sehingga mendapatkan hasil belajar yang baik. Sejalan dengan penelitian Skills (2017) mengatakan bahwa pembelajaran problem based learning menggunakan multimedia lebih baik daripada menggunakan modul terhadap prestasi belajar peserta didik. Proses pembelajaran dengan model PBL berbantuan media virtual pada tahap orientasi masalah di awal pembelajaran, masalah disajikan melalui media virtual sehingga siswa lebih termotivasi lagi dalam belajar dan lebih mudah memahami konsep dengan animasi yang ditampilkan melalui media virtual (Hastuti et al., 2016).

Model Problem Based Learning merupakan suatu model pembelajaran yang menggunakan masalah yang ada di sekitar peserta didik sebagai awal dari proses pembelajaran, kemudian masalah tersebut dianalisis oleh peserta didik dalam berkelompok, agar dapat melatih peserta didik untuk berfikir kritis dan memiliki keterampilan untuk memecahkan masalah sehingga peserta didik dapat memperoleh pemahaman tentang materi pelajaran dan kemampuan sosial peserta didik juga dapat dikembangkan menyeluruh dalam pembelajaran (Rahmadani \& Taufina, 2020). Model problem based learning ini merupakan model pembelajaran yang menyajikan berbagai permasalahan nyata dalam kehidupan seharihari siswa. Pembelajaran berbasis masalah terdiri atas serangkaian kegiatan pembelajaran yang dirancang untuk membantu siswa meningkatkan kemampuan berpikir kritisnya. pembelajaran yang berpusat pada siswa (student centered), sehingga proses pembelajaran lebih bermakna karena adanya pengalaman nyata dari siswa (Yunita et al., 2020). Pengalaman nyata inilah yang dapat memberikan kesan bermakna pada siswa, sehingga dapat memberikan peningkatan pada kemampuan berpikir kritis dan hasil belajar siswa. Dalam mengaplikasikan model problem based learning di dalam kelas, ada beberapa prosedur atau tahapan yang harus dilaksanakan dalam kegiatan belajar mengajar secara umum yaitu ;1) Orientasi peserta didik pada masalah; 2) mengorganisasikan peserta didik untuk belajar; 3) membimbing penyelidikan individu maupun kelompok; 4) mengembangkan dan menyajikan hasil karya, dan 5) menganalisis dan mengevaluasi proses pemecahan masalah

\section{METODE}

Prosedur penelitian yang akan dilakukan adalah model 4D yang dibagi menjadi 4 tahapan yaitu pendefinisian (define), perencanaan (design), pengembangan (develop) dan penyebaran (disseminate). Prosedur penelitian dapat dilihat pada gambar 1

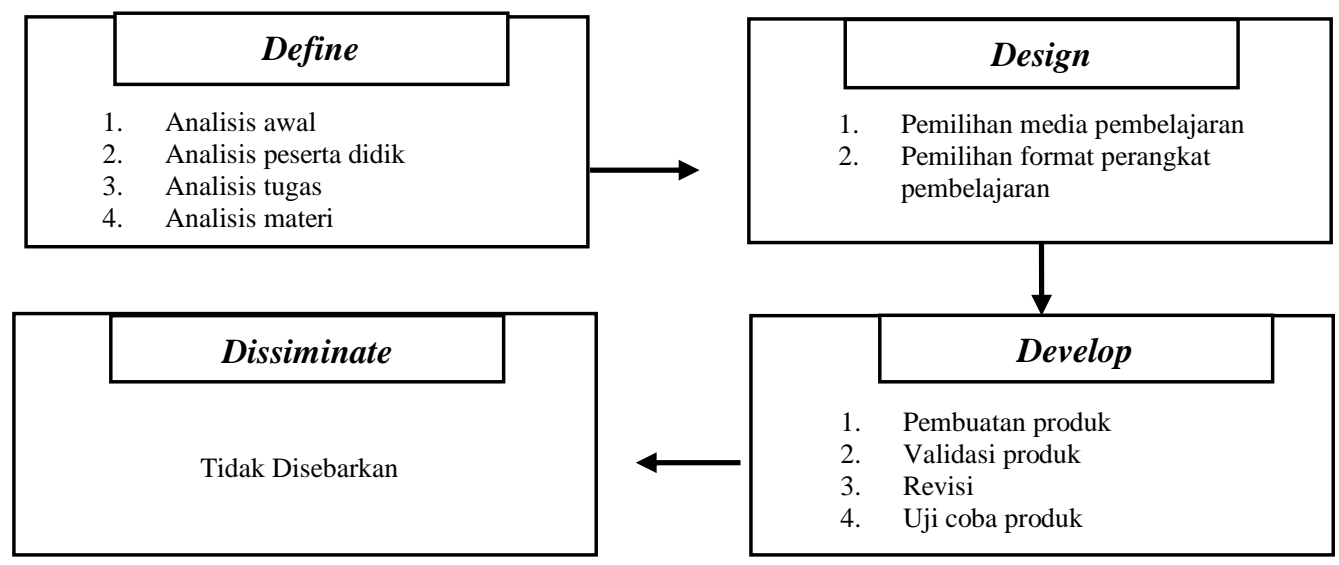




\section{Gambar 1. Prosedur penelitian model 4D}

Pada penelitian ini data yang digunakan adalah berupa angket atau konsioner. Data yang dianalisis dalam penelitian pengembangkan yaitu multimedia interaktif RPP, LKPD, silabus, dan instrumen tes adalah data kuantitatif. Data kuantitatif diperoleh dari hasil penilaian angket oleh validator ahli. Teknik analisis data hasil validasi ahli terhadap multimedia interaktif dilakukan melalui tahapan sebagai berikut:

$$
\text { Validasi }=\frac{\text { Jumlah skor dari penilai }}{\text { Jumlah seluruh aspek yang dinilai }}
$$

Tabel 1. Kriteria Penilaian validitas multimedia interaktif

\begin{tabular}{cll}
\hline No & Rentang Skor & Katagori \\
\hline 1 & $\bar{X} \geq 3,0$ & Sangat Baik \\
2 & $3,0>\bar{X} \geq 2,5$ & Baik \\
3 & $2,5>\bar{X} \geq 2,0$ & Kurang Baik \\
4 & $\bar{X}<2,0$ & Tidak Baik \\
\hline
\end{tabular}

Untuk menganalisis validitas dari silabus, RPP, LKPD, dan instrument tes dapat menggunakan tenik analisis validasi sebagai berikut:

$$
\text { Validitas }(V)=\frac{\text { Total skor validasi }}{\text { Total skor maksimal }} \times 100 \%
$$

Nilai skor validitas masing-masing yang diperoleh kemudian dikonversikan menjadi data kualitatif berupa tingkat kelayakan produk.Pedoman konversi nilai pada tabel 2

Table 2. Kriteria penilaian validitas perangkat pembelajaran

\begin{tabular}{cll}
\hline No & Rentang sekor & Katagori \\
\hline 1 & $75,01-100,00 \%$ & Sangat valid \\
2 & $50,01-75,00 \%$ & Cukup valid \\
3 & $30,01-50,00 \%$ & Kurang valid \\
4 & $01,00-30,00 \%$ & Tidak valid \\
\hline
\end{tabular}

(Sumber: Akbar, 2013)

Selanjutnya untuk menganalisis peningkatan hasil belajar peserta didik dapat diketahui melalui hasil pretest dan posttest. Hasil pretest dan posttest dianalisis menggunakan standar gain, dengan persamaan sebagai berikut.

$$
<g>=\frac{\text { Xposttest }- \text { Xpretes }}{\text { Xmaksimum-Xpretes }}
$$

Nilai stndar gain yang diperoleh dari hasil perhitungan kemudian di kategorikan sesuai tabel

Table 3. Standar gain penilaian hasil belajar

\begin{tabular}{cll}
\hline No & Nilai $\langle\boldsymbol{g}\rangle$ & Kategori \\
\hline 1 & $(g) \geq 0,7$ & Tinggi \\
2 & $0,7>(g) \geq 0,3$ & Sedang \\
3 & $(g)<0,3$ & Rendah \\
\hline
\end{tabular}




\section{HASIL DAN PEMBAHASAN}

Hasil dari penelitian ini adalah perangkat pembelajaran yang terdiri dari multimedia interaktif silabus, RPP, LKPD, dan instrumen tes hasil belajar. Perangkat pembelajaran yang pertama yaitu silabus, silabus yang dihasilkan disusun berdasarkan silabus yang telah ada dan dirancang kemudian disesuaikan dengan pemilihan model pembelajaran yaitu model PBL. Silabus sebagai dasar penyusunan RPP yang di dalamnya berisi Kompetensi Inti (KI), Kompetensi Dasar (KD), materi pokok, sintaks model model PBL, bentuk penilaian yang digunakan, alokasi waktu, dan sumber belajar.

Perangkat pembelajaran yang kedua yaitu RPP, untuk kegiatan pembelajarannya disesuaikan dengan sintaks model pembelajaran PBL yang meliputi: Orientasi peserta didik pada masalah, mengorganisasikan peserta didik untuk belajar, membimbing penyelidikan individu maupun kelompok, mengembangkan dan menyajikan hasil karya, dan menganalisis dan mengevaluasi proses pemecahan masalah

Perangkat pembelajaran yang ketiga yaitu multimedia interaktif. Multimedia interaktif yang dikembangkan mengikuti sintaks model PBL dengan dilengkapi dengan simulasi untuk menyelesaikan permasalahan yang diberikan saat pembelajaran dan inforrmasi tambahan sperti tabel sudut istimewa.

Keempat yaitu LKPD, LKPD dibuat berdasarkan tujuan pembelajaran yang disesuaikan dengan model PBL. Peserta didik diarahkan melakukan percobaan eksperimen untuk menyelesaikan permasalahan atau menemukan jawaban dari sebuah pertanyaan yang tercantum pada LKPD.

Kelima yaitu instrumen tes hasil belajar, instrumen tes ini digunakan untuk mengukur hasil belajar peserta didik pada ranah kognitif yaitu kemampuan mengingat, memahami, mengaplikasikan, menganalisis, mengevaluasi, dan mencipta. Instrumen tes dibuat dalam bentuk pilihan ganda yang berisi 10 butir soal dan 5 butir soal essay.

Hasil validasi multimedia interaktif dari segi materi dan media sebagai berikut:

Tabel 4. Hasil validasi multimedia interaktif

\begin{tabular}{lll}
\hline Aspek yang dinilai & $\overline{\boldsymbol{X}}$ skor & Katagori \\
\hline Materi & 2,98 & Baik \\
Media & 3,26 & Sangat Baik \\
Rata-Rata & 3,12 & Sangat Baik \\
\hline
\end{tabular}

Berdasarkan penilaian validitas multimedia interaktif dari aspek materi dan media menggunakan angket validasi maka dapat disimpulkan bahwa multimedia interaktif layak digunakan dengan katagori sangat baik.

Tabel 5. Hasil validasi perangkat pembelajaran

\begin{tabular}{lll}
\hline Validator & Persentase $(\%)$ & Katagori \\
\hline Silabus & 78,08 & Sangat Valid \\
RPP & 73,66 & Cukup Valid \\
LKPD & 75,5 & Sangat Valid \\
Instrumen tes & 77,6 & Sangat Valid \\
\hline
\end{tabular}

Berdasarkan penilaian validitas dari silabus, RPP, LKPD dan instrumen tes menggunakan angket validasi maka dapat disimpulkan bahwa perangkat pembelajaran layak digunakan dengan katagori berturut turut sangat valid, cukup valid, sangat valid, sangat valid. 
Tabel 6. Respon peseta didik terhadap multimedia interaktif

\begin{tabular}{llll}
\hline Jumlah pernyataan & Total Responden & $\overline{\boldsymbol{X}}$ skor & Katagori \\
\hline 12 & 20 & 3,04 & Sangat Baik \\
\hline
\end{tabular}

Berdasarkan penilaian respon peseta didik terhadap multimedia interaktif menggunakan angket respon maka dapat disimpulkan bahwa multimedia interaktif layak digunakan dengan katagori sangat baik

Tabel 7. Nilai N-gain peserta didik

\begin{tabular}{cccc}
$\overline{\boldsymbol{X}}$ pre & $\overline{\boldsymbol{X}}$ post & N-Gain & Katagori \\
\hline 16,73 & 59,7 & 0,49 & Sedang \\
\hline & Berdasarkan proses pembelajan yang telah dikuti oleh peserta & didik mengounakan
\end{tabular}

multimedia interaktif berbasis PBL maka dapat disimpulkan bahwa hasil belajar peserta didik mengalami peningkatan dengan nilai $\mathrm{N}$-gain katagori sedang.

\section{Validitas perangkat pembelajaran}

Berdasarkan data yang diperoleh dari hasil valiadasi dan hasil uji coba mengacu pada teknik analisis data yang telah dilakukan, diperoleh hasil kelayakan multimedia interaktif untuk materi gerak parabola dengan rata-rata penilaian ahli materi dan ahli media sebesar 2,98 dan 3,26. Penilaian multimedia interaktif dari validator ahli dan peserta didik digabungkan sehingga rata ratanya menjadi 3,12 dan memiliki katagori sangat baik untuk digunakan. Hasil validasi silabus, RPP, LKPD dan instrument tes didapatkan persentase berturut-turut yaitu 78,68\%,73,65\% , 75,5\%,77,6\% sehingga layak digunakan untuk kegiatan pembelajaran. Penelitian yag dilakukan oleh Istiqamah (2019) yang mengatakan suatu desain intervensi atau produk khususnya pengembangan perangkat pembelajaaran akan bertambah kuat apabila telah divalidasi sehingga kualitas perangkat pembelajaran tersebut tidak diragukan lagi. Perangkat pembelajaran dikatakatan valid apabila memenuhi kriteria validitas. Menurut Sugiyono (2015) validitas dan reabilitas instrumen penelitian merupakan hal utama dalam meningkakan efektivitas proses pengumpulan data.

\section{Kepraktisan multimedia interaktif}

Keperaktisan didapatkan dari angket respon peserta didik terhadap multimedia interaktif. Hasil pengisian angket respon oleh peserta didik terhadap multimedia interaktif yang dikembangkan menujukan bahwa multimedia interaktif praktis digunakan untuk proses pembelajaran. Multimedia interaktif berbasis PBL dikatakan praktis karna penggunaannya yang mudah kemudian isi materi dilengkapi dengan gambar, simulasi, tulisan, dan suara yang jelas serta memiliki tampilan berupa gambar dan animasi yang menarik yang mampu membantu peserta didik dalam memecahkan masalah yang diberikan oleh guru saat proses pembelajaran. Berdasarkan analisis angket respon peserta didik terhadap keperaktisan multimedia interaktif berbasis problem based learning pada materi gerak parabola didapatkan rata rata skor respon peserta didik adalah 3,04 katagori baik atau praktis untuk digunakan dalam kegiatan pembelajaran. Hal ini sesuai dengan penelitian dari Usman (2002) bahwa pemanfaatan media pembelajaran juga tidak lepas dari fungsi media pembelajaran tersebut. Pada awalnya media hanya berfungsi sebagai alat bantu dalam kegiatan belajar mengajar, yakni berupa sarana yang dapat memberikan pengalaman visual kepada siswa dalam rangka mendorong motivasi belajar, memperjelas dan mempermudah konsep yang kompleks dan abstrak menjadi lebih sederhana, kongkrit, serta mudah dipahami.

\section{Keefektifan multimedia interaktif}

Aspek keefektifan produk multimedia interaktif berbasis problem based learning diperoleh berdasarkan analisis data hasil belajar peserta didik pada uji coba terbatas. Hasil 
belajar peserta didik untuk materi gerak parabola memilki nilai $\bar{X}$ pretest yaitu 16,73 dan nilai $\bar{X}$ posttest 59,70 sehingga didapatkan nilai N-Gain sebesar 0,49 sehingga memilki katagori sedang dan terdapat peningakatan hasil belajar peserta didik untuk materi gerak parabola dengan menggunakan multimedia interaktif berbasis problem based learning. Hasil penelitian yang mendukung penelitian ini adalah penelitian yang dilakukan oleh Ridwan dkk (2021) yang menghasilkan multimedia interaktif berbasis PBL yang reliabel karena percentage agreement (PA) diatas $75 \%$ dan mampu meningkatkan hasil belajar dengan nilai N-Gain sebesar 0,60 dengan katagori sedang. Model PBL sangat efektif digunakan dalam multimedia interaktif, hal isi sesuai dengan penelitian Celik et al (2011) yang mengatakan adanya perubahan yang signifikan dalam penggunakan model PBL yang dibuktikan dengan prolehan data hasil belajar. Menurut Selcuk \& Caliskan (2010) dalam penelitianya mengatakan bahwa siswa yang menerima pengajaran fisika dalam format PBL menunjukkan sikap yang lebih positif terhadap pelajaran fisika daripada rekan-rekan mereka yang menerima pengajaran tradisional. Rahmani et al (2013) dalam penelitianya model game berbasis masalah bahwa terdapat peningkatan kemampuan, keterampilan dan pemerosesan kinerja yang meningkat pada peserta diik. Selanjutnya penelitian pengembangan yang serupa dilakukan oleh Khamzawi \& Wiyono (2015) multimedia interaktif yang dikembangkan telah dinyatakan sangat valid dan sangat praktis tetapi hanya dapat meningkatkan hasil belajar berdasarkan nilai N-Gain dengan kategori sedang. Penggunaan multimedia interaktif berbasis PBL dapat membuat peserta didik mampu memecahkan masalah bersama teman kelompok yang sudah dibentuk sehingga mreka mampu berbagi pemahaman yang mreka dapatkan saat proses pembelajaran. Hal ini sesuai dengan penelitian Sulaiman (2010) yang mengatakan bahwa kolaborasi membantu para peserta bekerja lebih baik sebagai anggota kelompok, dan mereka merasakannya dengan mendiskusikan masalah, mereka bisa memecahkan masalah yang mereka hadapi selama intervensi.

Berdasarkan pengembangan multimedia interaktif berbasis problem based learning pada materi gerak parabola, maka multimedia interaktif ini dianggap berhasil dikembangkan menjadi media yang valid, praktis, efektif dan lebih baik sehingga layak digunakan untuk pembelajaran di kelas dan telah sesuai dengan tahap pengembangan serta mampu memberikan manfaat bagi peserta didik

\section{KESIMPULAN}

Berdasarkan hasil penelitian dan pembahasan, dapat diambil kesimpulan bahwa validitas perangkat pembelajaran berbasis problem based learning yang dikembangkan berdasarkan hasil validasi oleh validator ahli terhadap multimedia interaktif, silabus, RPP, LKPD, dan instrumen tes hasil belajar diperoleh: Multimedia interaktif layak untuk digunakan dengan rata rata validitas 3,09 dan memiliki kreteria sangat baik. Silabus layak untuk digunakan dengan persentase rata rata yaitu 78,68\% sehingga silabus memiliki katagori sangat valid. RPP layak untuk digunakan dengan persentase rata rata yaitu $73,65 \%$ sehingga RPP memiliki katagori cukup valid. LKPD layak untuk digunakan dengan persentase rata rata yaitu 75,5\% sehingga LKPD memiliki katagori sangat valid. Instrumen tes layak untuk digunakan dengan persentase rata rata yaitu 77,6\% sehingga instrumen tes memiliki katagori sangat valid; Multimedia interaktif berbasis problem based learning yang dikembangkan praktis digunakan oleh peserta didik dengan rata rata skor respon peserta didik adalah 3,04 katagori baik atau praktis untuk digunakan dalam kegiatan pembelajaran; Multimedia interaktif berbasis problem based learning yang dikembangkan efektif digunakan oleh peserta didik. Hasil belajar peserta didik untuk materi gerak parabola memilki nilai $\bar{X}$ pretest yaitu 16,73 dan nilai $\bar{X}$ posttest 59,70 sehingga didapatkan nilai $\mathrm{N}$-Gain sebesar 0,49 memilki katagori sedang dan terdapat peningakatan hasil belajar peserta didik. 


\section{SARAN}

Berdasarkan hasil penelitian, untuk mencapai tujuan peningkatan hasil belajar peserta didik serta untuk penerapan pembelajaran dengan multimedia interaktif berbasis PBL yang lebih baik lagi, peneliti menyarankan beberapa hal sebagai berikut: Multimedia interaktif yang dikembangkan sebaiknya bisa diakses di handphone android supaya peserta didik dapat dengan mudah belajar di rumah menggunakan multimedia interaktif karena tidak semua peserta didik dapat menggunakan laptop atau komputer karna keterbatasan biaya, sedangkan untuk guru sebaiknya tetap menggunakan laptop supaya bisa memperbaiki komponen yang salah dalam media untuk digunakan mengajar; Materi yang dikembangkan pada multimedia interaktif sebaiknya bervariasi karena peserta didik senang diajar menggunakan media yang baru dikenal sehingga materi selanjutnya yang diajarkan dapat menggunakan media yang sama; Pembuatkan multimedia interaktif menggunakan Adobe Flash Pro CS6 sebaiknya jangan menggunakan banyak scene dan lebih baik menggunakan frame, gambar yang digunakan sebagai background dan video yang dimasukkan diubah kapasitasnya menjadi lebih kecil supaya multimedia interaktif yang dibuat ukuran penyimpanannya lebih kecil

\section{DAFTAR PUSTAKA}

Awwaliyah, R. (2018). Pendidikan Islam Dalam Sistem Pendidikan Nasional. Jurnal Ilmiah Didaktika,(19)(1), 34-49

Celik, P., Onder, F., \& Silay, I. (2011). The Effects Of Problem-Based Learning On The Students' Success In Hysics Course. Procedia - Social and Behavioral Sciences, 28, 656-660.

Hastuti, A.,Sahidu, H. dan Gunawan. 2016. Pengaruh Model PBL Berbantuan Media Virtual Tehadap Kemampuan Pemecahan Masalah Fisika. Jurnal Pendidikan Fisika dan Teknologi, 2(3), 129-135.

Istiqamah, (2019). Validitas Perangkat Pembelajaran Konsep Pencemaran Lingkungan Untuk Meningkatkan Keterampilan Komunikasi Sains Siswa SMA di Banjarmasin. Jurnal Ilmiah Kependidikan. 8(2), 117-124.

Khamzawi, S., \& Wiyono, K. (2015). Pengembangan Multimedia Interaktif Berbasis Model Pembelajaran Problem Based Leaning Pada Mata Pelajaran Fisika Pokok Bahasan Fuida Dinamis Untuk SMA Kelas XI. Jurnal Inovasi Dan Pembelajaran Fisika, 2(1), 100-108.

Rafmana, H., Chotimah, U., \& Alfiandra. (2018). Pengembangan Multimedia Interaktif Berbasis Articulate Storyline Untuk Meningkatkan Motivasi Sma Srijaya Negara Palembang. Jurnal Bhinneka Tunggal Ika, 5(1), 52-65.

Rahmadani, R., \& Taufina, T. (2020). Pengembangan Multimedia Interaktif Berbasis Model Problem Based Learning (PBL) Bagi Siswa Sekolah Dasar. Jurnal Basicedu, 4(4), 938-946.

Rahmani, R., Abbas, M., \& Alahyarizadeh, G. (2013). The Effects Of Peer Scaffolding In Problem-Based Gaming On The Frequency Of Double-Loop Learning And Performance In Integrated Science Process Skills. Procedia - Social and Behavioral Sciences, 93, 1994-1999

Rahmawati \& Dewi .(2019). Penggunaan Multimedia Interaktif (MMI) Sebagai Media Pembelajaran Dalam Meningkatkan Prestasi Belajar Fisika. Jurnal Pendidikan Fisika dan Teknologi, 5(1), 51-58.

Ridwan, Y. H., Zuhdi, M., Kosim, K., \& Sahidu, H. (2021). Pengembangan Media Pembelajaran Interaktif Berbasis Model Problem Based Learning Untuk Meningkatkan Kemampuan Berpikir Kreatif Fisika Peserta Didik. ORBITA: Jurnal Kajian, Inovasi Dan Aplikasi Pendidikan Fisika, 7(1), 103-108. 
Selçuk, G. S., \& Çalişkan, S. (2010). A Small-Scale Study Comparing The Impacts Of Problem-Based Learning And Traditional Methods On Student Satisfaction In The Introductory Physics Course. Procedia - Social and Behavioral Sciences, 2(2), 809813

Skills, S. (2017). Pengembangan Multimedia Interaktif Bervisi SETS sebagai Alat Bantu Model Problem Based Learning (PBL) dalam Pembelajaran IPA di SMP untuk Meningkatkan Kemampuan Berpikir Kritis dan Keterampilan Sosial Peserta Didik. Pancasakti Science Education Journal. 2(2), 125-137.

Sugiyono, (2015). Metode Penelitian Tindakan Komprenhensif. Yogyakarta: Alfabeta

Sujono, H.D. (2017). Multimedia Pembelajaran interaktif. Yogyakarta:UNY press

Sulaiman, F. 2010. Students' Perceptions Of Implementing Problem-Based Learning In A Physics Course. Procedia - Social and Behavioral Sciences, 7(2), 355-362.

Usman \& Basyiruddin. (2002). Media Pembelajaran. Jakarta: Ciputat Press

Wiyono, K. (2015). Pengembangan Multimedia Interaktif Berbasis Model Pembelajaran Problem Based Learning Pada Mata Pelajaran Fisika Pokok Bahasan Fluida Dinamis Untuk Sma Kelas XI. Jurnal Inovasi dan Pembelajaran Fisika. 2(1), $100-108$.

Syahidi, K., Hizbi, T., Hidayanti, A., Ditinjau, B., Kemampuan, D., \& Kritis, B. (2020). The Effect of PBL Model Based Local Wisdom Towards S tudent's Learning Achievements on Critical Thinking Skills Pengaruh Model PBL Berbasis Kearifan Lokal Terhadap Prestasi. Kasuari: Physics Education Journal ( KPEJ ) Universitas Рариа, 3(1), 61-68.

Yunita, N., Zahara, L., \& Syahidi, K. (2020). Pengaruh Model Problem Based Learning (PBL) Melalui Lesson Study Terhadap Kemampuan Berpikir Kritis Siswa. Kappa Journal, 4(2), 233-239. https://doi.org/10.29408/kpj.v4i2.2756 